\title{
Analysis Fatty Acids Profile in Tabanus bivittatus Mats with Gas Chromatography-Mass Spectrometry
}

\author{
Wang Yanhua*, Wu Fuhua, Guo Zhaohan, Peng Mingxing, Xia Min, Pang Zhenling, Wang Xiaoli, \\ Liang Zian and Zhang Naiqun
}

Life Science and Technology College, Nanyang Normal University, Henan Province, China

\begin{abstract}
Tabanus bivittatus Mats., a traditional Chinese medicine, is commonly used for cardiovascular disorders treatment including atherosclerosis. There have been only a few researches on its chemical components, and no detailed report has appeared on its fatty acids. To develop a simple and effective method for the extraction of total fatty acids from Tabanus bivittatus Mats., the Soxhlet extraction (SE) condition was optimized with response surface methodology. The fatty acid composition of the extract were determined by GC-MS with previous derivatization to fatty acid methyl esters (FAMEs). The major fatty acids in Tabanus bivittatus Mats. were oleic acid, palmitic acid, linoleic acid, palmitoleic acid, and stearic acid, and the unsaturated fatty acids occupy $63.9 \%$ of the total fatty acids.
\end{abstract}

Keywords: Fatty acid, gas chromatography, mass spectrometry, response surface methodology, Tabanus bivittatus Mats.

\section{INTRODUCTION}

As a traditional Chinese medicine, Tabanus bivittatus Mats. is known to have a regulatory property for blood circulation and inflammatory disease [1, 2]. This natural product is one of the major drugs used in the Chinese traditional medicine Da Huang Zhe Chong pill to treat hepatic cirrhosis [3], atherosclerosis, and menstrual disturbance [4]; these actions are probably produced by pharmacodynamic activity on vascular system. Up to now, there have been only a few researches on the chemical componets of Tabanus bivittatus Mat. [5], but no detailed report has appeared on its fatty acid components.

A variety of chromatographic techniques have been employed in the analysis of fatty acids, such as high performance liquid chromatography [6, 7], gas chromatography[8, 9]. A way to decrease the limit of quantification and provide a higher level of information is to use a gas chromatograph (GC) equipped with an MS detector, which allows quantification of each individual compound [10].

Soxhlet extraction (SE) is a classical method for decades in extraction of organic compounds from solid sample, and this apparatus has been developed to several types for special used. It is considered to be a "thorough" extraction method because th organic phase cooled from condensation tube continuously passed through the target solid sample for hours. Therefore it is a popular technique to analysis the minor composition file of the solid sample although high organic solvent volume, extensive extraction time, and intensive manpower are required [11].

*Address correspondence to this author at the School of Life Science and Technology, Nanyang Normal University, Nanyang, Henan,473000, P.R. China; Tel: +86 18567179077; E-mail: wanga_yanhua@163.com
In this paper, SE followed by GC-MS was developed for the rapid analysis of fatty acids in Tabanus bivittatus Mats.. The experimental parameters were optimized with RSM in order to obtain the greatest extraction yield of fatty acids, and the fatty acid compositions of extract were determined by GC-MS with previous derivatisation to FAMEs.

\section{EXPERIMENT DESIGN OF THE OPTIMIZATION OF EXTRACTION CONDITION WITH RSM}

Response surface methodology (RSM) is a collection of statistical and mathematical techniques useful for developing, improving, and optimizing processes in which a response of interest is influenced by several variables [12], and has been widely applied to the optimization of the extraction procedureparameters $[13,14]$.

A three-level-three-variable Box-Behnken design (BBD) was adopted to optimize the extraction procedure. The independent variables were extractant volume $(\mathrm{V}, \mathrm{mL})$, extraction time ( $\mathrm{T}, \mathrm{min})$, and ratio of acetone and petroleum ether (R). Three levels of each variable were coded as $-1,0$, and +1 (Table 1). The extraction yield, represented as the weight of oil extracted form Tabanus bivittatus Mats., was taken as response, Y. A regression analysis was carried out in order to fit the experimental data into an empirical secondorder polynomial model.

The variables and levels for each variable in BBD were determined according to the results of preliminary experiments. Based on the experimental results of the BBD (Table 1), the extraction yield followed a second-order polynomial model.

Where Y represented the extraction yield, calculated by the weight of oil extracted form Tabanus bivittatus Mats.; V, $\mathrm{R}$ and $\mathrm{T}$ correspond to three independent variables, 
Table 1. Box-Behnken design and experiment results for the optimization of SE

\begin{tabular}{|c|c|c|c|c|c|}
\hline \multirow[t]{2}{*}{ Run } & \multirow{2}{*}{$\begin{array}{l}\text { Petrole um } \\
\text { ether }\end{array}$} & \multirow{2}{*}{$\begin{array}{l}\text { Ext raction volume } \\
\qquad(\mathrm{V}, \mathrm{ml})\end{array}$} & \multirow{2}{*}{$\begin{array}{c}\text { Extraction time } \\
(t, h)\end{array}$} & \multicolumn{2}{|c|}{ Re sponse (extr action } \\
\hline & & & & yield) & \\
\hline & /acet one(R) & & & Observed & Predicted \\
\hline 1 & $1(-1)$ & $50(0)$ & $2(+1)$ & 0.43 & 0.38 \\
\hline 2 & $9(+1)$ & $50(0)$ & $0.3(-1)$ & 0.48 & 0.44 \\
\hline 3 & $5(0)$ & $50(0)$ & $1.15(0)$ & 0.59 & 0.49 \\
\hline 4 & $9(+1)$ & $80(+1)$ & $1.15(0)$ & 0.52 & 0.51 \\
\hline 5 & $5(0)$ & $50(0)$ & $1.15(0)$ & 0.56 & 0.40 \\
\hline 6 & $5(0)$ & $80(+1)$ & $2(+1)$ & 0.63 & 0.44 \\
\hline 7 & $1(-1)$ & $20(-1)$ & $1.15(0)$ & 0.37 & 0.47 \\
\hline 8 & $5(0)$ & $20(-1)$ & $0.3(-1)$ & 0.41 & 0.51 \\
\hline 9 & $1(-1)$ & $80(+1)$ & $1.15(0)$ & 0.5 & 0.44 \\
\hline 10 & $5(0)$ & $50(0)$ & $1.15(0)$ & 0.61 & 0.50 \\
\hline 11 & $5(0)$ & $20(-1)$ & $2(+1)$ & 0.54 & 0.49 \\
\hline 12 & $5(0)$ & $50(0)$ & $1.15(0)$ & 0.58 & 0.60 \\
\hline 13 & $5(0)$ & $80(+1)$ & $0.3(-1)$ & 0.45 & 0.58 \\
\hline 14 & $1(-1)$ & $50(0)$ & $0.3(-1)$ & 0.44 & 0.58 \\
\hline 15 & $9(+1)$ & $20(-1)$ & $1.15(0)$ & 0.43 & 0.58 \\
\hline 16 & $9(+1)$ & $50(0)$ & $2(+1)$ & 0.47 & 0.58 \\
\hline 17 & $5(0)$ & $50(0)$ & $1.15(0)$ & 0.58 & 0.58 \\
\hline
\end{tabular}

$\mathrm{Y}=0.126+0.066 \mathrm{P}+5.561 \mathrm{~V}+0.139 \mathrm{~T}-8.33 \mathrm{E}-005 \mathrm{P} * \mathrm{~V}+0.00 \mathrm{P} * \mathrm{~T}+4.901 \mathrm{E}-004 \mathrm{~V} * \mathrm{~T}-5.671 \mathrm{E}-003 \mathrm{P} 2-4.250 \mathrm{E}-005 \mathrm{~V} 2-0.529 \mathrm{~T} 2$

extractant volume ( $\mathrm{mL}$, for $10.0 \mathrm{~g}$ sample), ratio of acetone and petroleum ether, and extraction time (min).

The statistical analysis of our model variance and experimental results was included in Table 2 . The F-value of our model is 3.96 which is significant. The chance that a 'Model F-Value' this large could occure due to noise was only $4.15 \%$. The linear terms of extractant volume, and quadratic terms of proportion of acetone and petroleum ether had statistically significant effects on extraction yield. This is indicated by the B, A2 were significant model terms ( $\mathrm{p}<$ 0.05 ). The coefficient determination in our model was 0.8360 .

The best way to visualize the influence of independent variables on the dependent one is to draw a surface response plot of the model. With a fixed third independent variable at the central experimental level of zero, Fig. (1) showed the 
Table 2. Analysis of variance (ANOVA) for the model

\begin{tabular}{|c|c|c|c|c|c|}
\hline Source & Sum of squares & $\mathrm{df}^{\mathrm{a}}$ & Mean square & F Value & $p$-value \\
\hline M odel & 0.081 & 9 & $9.031 \mathrm{E}-003$ & 3.96 & $0.0415^{b}$ \\
\hline $\mathrm{R}$ & $3.200 E-003$ & 1 & $3.200 \mathrm{E}-003$ & 1.40 & 0.2746 \\
\hline V & 0.015 & 1 & 0.015 & 6.72 & $0.0358^{b}$ \\
\hline $\mathrm{t}$ & 0.011 & 1 & 0.011 & 4.62 & 0.0688 \\
\hline RV & $4.000 E-004$ & 1 & $4.000 \mathrm{E}-004$ & 0.18 & 0.6877 \\
\hline $\mathrm{Rt}$ & 0.000 & 1 & 0.000 & 0.000 & 1.0000 \\
\hline Vt & $6.250 E-004$ & 1 & $6.250 \mathrm{E}-004$ & 0.27 & 0.6166 \\
\hline $\mathrm{R}^{2}$ & 0.035 & 1 & 0.035 & 15.22 & $0.0059^{b}$ \\
\hline $\mathrm{V}^{2}$ & $6.160 E-003$ & 1 & $6.160 \mathrm{E}-003$ & 2.70 & 0.1441 \\
\hline $\mathrm{T}^{2}$ & $6.160 \mathrm{E}-003$ & 1 & $6.160 \mathrm{E}-003$ & 2.70 & 0.1441 \\
\hline Residual & 0.016 & 7 & $2.278 \mathrm{E}-003$ & & \\
\hline Lack of fit & 0.015 & 3 & $4.875 E-003$ & 14.77 & 0.0125 \\
\hline Pure error & $1.320 \mathrm{E}-003$ & 4 & $3.300 \mathrm{E}-004$ & & \\
\hline Cor total & 0.097 & 16 & & & \\
\hline R-Squared & 0.8360 & & & C.V.\% & 9.45 \\
\hline
\end{tabular}

a df, degree of fr eedom

b Significance, $p<0.05$

effect and interaction of two independents on the responding variable, extraction yield. The extraction yield was increased with the increase of extractant volume up to about $70.0 \mathrm{ml}$, and then decreased. In contrast, the effects of ratio of acetone and petroleum ether and extraction time were not as important as the extractant volume. These results revealed that the extraction yield of total fatty acids was depended more on extractant volume than on ratio of acetone and petroleum ether and extraction time.

\section{IMPACT OF EXTRACTING TIMES}

The influence of multiple extracting was explored on the total extraction rate of fatty acids at the optimized condition. Fig. (2). showed that the total extraction rate of fatty acids increased with the extracting times, and the fatty acids were extracted entirely after 5 times. Considering the extraction cost and the total extraction rate increasing slightly over 3 times, extraction 3 times was selected as the optimum condition, at which the rate was $98.9 \%$ of that of 5 times. 

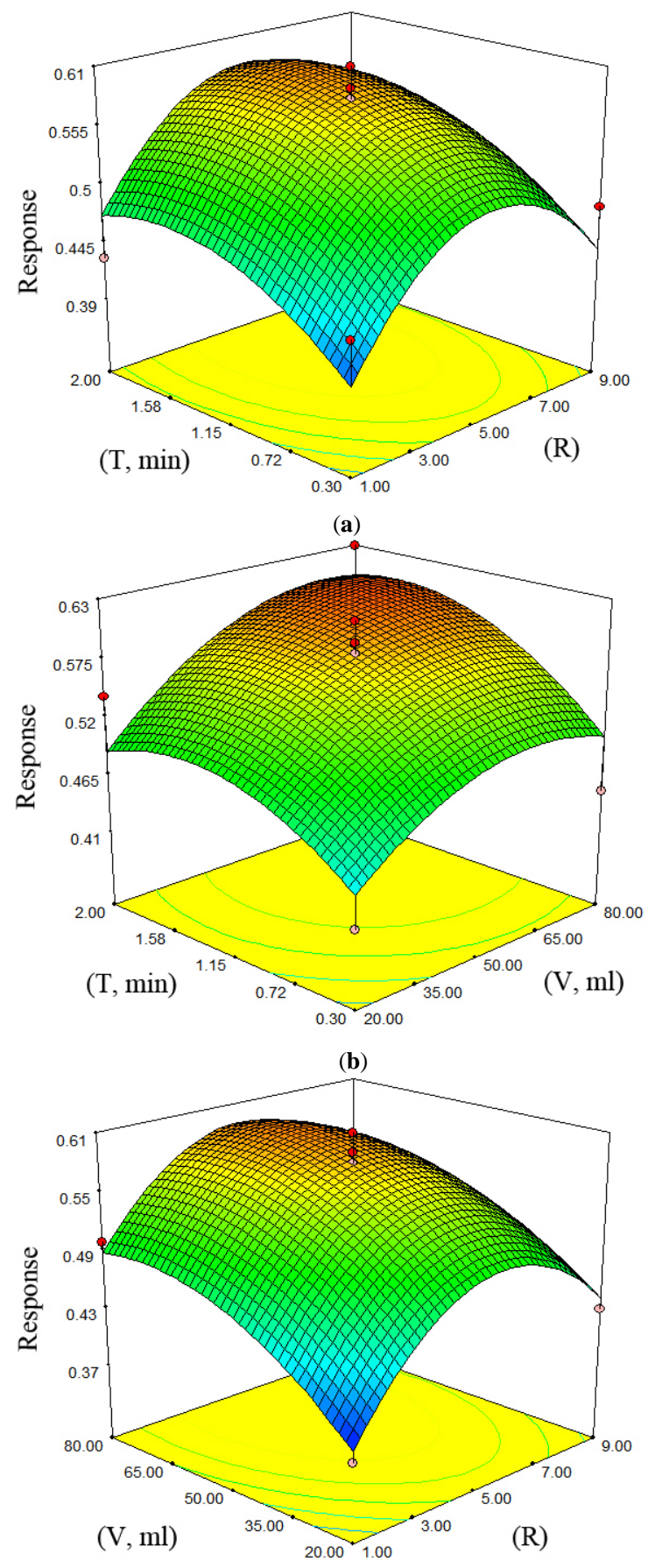

(c)

Fig. (1). (a) Response surface for the effects of extract time (T, min) and ratio of acetone and petroleum ether (R) at extractant volume of $50 \mathrm{ml}$ on the extraction yield. (b) Response surface for the effects of extract time ( $\mathrm{T}, \mathrm{min})$ and extractant volume $(\mathrm{V}, \mathrm{mL})$ at ratio of acetone and petroleum ether (R) of 5 on the extraction yield. (c) Response surface for the effects of extractant volume (V, $\mathrm{mL}$ ) and ratio of acetone and petroleum ether (R) at extractant time $75 \mathrm{~min}$ on the extraction yield.

\section{SYSTEM ANALYSIS OF CERAMIC DESIGN SYSTEM}

After soxhlet extraction, the fatty acids in the extract were derivatized to FAMEs with sulphuric acid-methanol complex, and then analyzed with GC-MS. Complex, and then analyzed with GC-MS. The analytical results were listed in Table 3 . The relative contents were calculated by using the area normalization method, without considering response factors. Twenty-one kinds of fatty acids in the SE extract were identified and the sum of identified fatty acids occupied $95.95 \%$ of the area normalized. It can be seen from Table 3. that Tabanus bivittatus Mats. is remarkably rich in oleic acid (33.38\%) and palmitic acid (20.96\%) followed by linoleic acid (19.03\%), palmitoleic acid (7.59\%), stearic acids (7.53\%). the unsaturated fatty acids occupy $63.92 \%$ of the total fatty acids. This result is consistent with the regulatory property of Tabanus bivittatus Mats. for blood circulation. Researches have identified that unsaturated fatty acids are effective in preventing cardiovascular events, cardiac death and coronary events, especially in persons with high cardiovascular risk. The high content of unsaturated fatty acids in Tabanus bivittatus Mats maybe the reason for it was used in cardiovascular disease treatment in China.

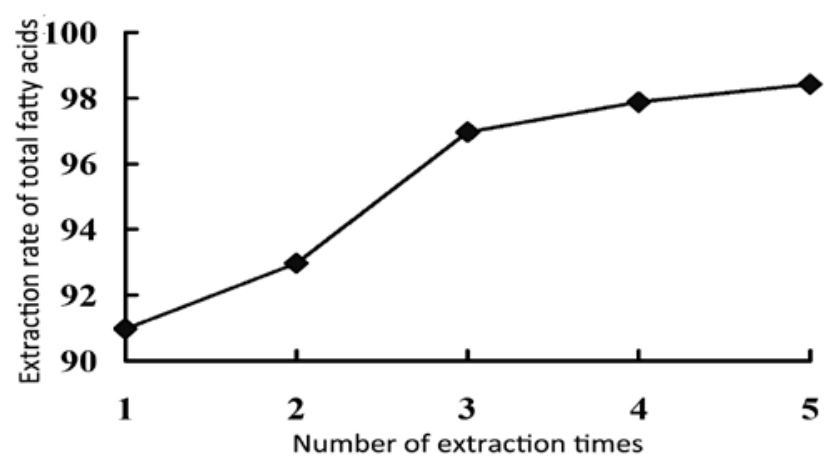

Fig. (2). Effect of extraction times on extraction rate of total fatty acids

\section{Analysis of Fatty Acids in Tabanus bivittatus Mats.}

The current ceramic enterprises in ceramic product design process and production process of detailed study, the design process of ceramic products for further analysis and decomposition, Exploring the project design of ceramic needs human interaction steps in the 3d CAD system, and needs to be done by the system automatically in order to better improve enterprise's key steps in the efficiency of product design and in the decomposition on the basis of the design process to classify modeling of ceramic products, and finished components decomposition of complex products. Ceramic products decomposition is different from the mechanical parts and components industry and other industry products, ceramic products decomposition lies mainly in the design of the components in the process of decomposition, and the final product in general is not an integral whole, for example, in the design process for more complex products such as "pot" will be broken down parts into the pot body, the pot, a spout, the lid and lid knob, a girder of the pot, an ear piece [10]. And set up all kinds of parts in the three-dimensional model of the material library.

\section{CONCLUSION}

To extract fatty acid of Tabanus bivittatus Mats., the best condition including extractant volume of $69.71 \mathrm{~mL}$, ratio of acetone and petroleum ether of 5.3 and extraction time of 
Table 3. Analytical results of fatty acids in Tabanus bivittat us Mats. By GC-MS( $n=3$ )

\begin{tabular}{|c|c|c|c|c|}
\hline $\begin{array}{l}\text { Retent ion } \\
\text { Time(min) }\end{array}$ & Fatty a cid & $\begin{array}{l}\text { Molecular } \\
\text { formula }\end{array}$ & $\begin{array}{l}\text { Relative } \\
\text { Molecular } \\
\text { weight }\end{array}$ & $\begin{array}{l}\text { Relative } \\
\text { content }\end{array}$ \\
\hline 3.49 & undec-10-eno ic acid & $\mathrm{C}_{11} \mathrm{H}_{20} \mathrm{O}_{2}$ & 184 & 0.22 \\
\hline 3.86 & Lauric acid & $\mathrm{C}_{12} \mathrm{H}_{24} \mathrm{O}_{2}$ & 198 & 0.07 \\
\hline 4.62 & Tridecylic acid & $\mathrm{C} 14 \mathrm{H} 28 \mathrm{O} 2$ & 228 & 0.06 \\
\hline 4.73 & Tetradeca noic acid & $\mathrm{C} 14 \mathrm{H} 28 \mathrm{O} 2$ & 228 & 0.55 \\
\hline 5.14 & i-Pentad ecan oic acid & $\mathrm{C} 15 \mathrm{H} 30 \mathrm{O} 2$ & 242 & 0.20 \\
\hline 5.32 & Pentadeca no ic acid, & $\mathrm{C} 15 \mathrm{H} 30 \mathrm{O} 2$ & 242 & 0.42 \\
\hline 5.77 & iso-hexadecenoic acid & $\mathrm{C} 16 \mathrm{H} 32 \mathrm{O} 2$ & 250 & 0.32 \\
\hline 5.91 & palmitoleic acid & $\mathrm{C} 16 \mathrm{H} 30 \mathrm{O} 2$ & 254 & 7.59 \\
\hline 5.98 & (Z)-9-Hexadecenoic acid & $\mathrm{C} 15 \mathrm{H} 30 \mathrm{O} 2$ & 254 & 1.13 \\
\hline 6.07 & palmitic acid & $\mathrm{C} 16 \mathrm{H} 32 \mathrm{O} 2$ & 256 & 20.96 \\
\hline 6.94 & marga ric acid & $\mathrm{C} 17 \mathrm{H} 34 \mathrm{O} 2$ & 270 & 0.82 \\
\hline 7.70 & linoleic acid & $\mathrm{C} 18 \mathrm{H} 32 \mathrm{O} 2$ & 280 & 19.03 \\
\hline 7.78 & oleic acid & $\mathrm{C} 18 \mathrm{H} 34 \mathrm{O} 2$ & 282 & 33.38 \\
\hline 7.92 & Linolenic acid & $\mathrm{C} 18 \mathrm{H} 30 \mathrm{O} 2$ & 278 & 0.29 \\
\hline 8.03 & stear ic acids & $\mathrm{C} 18 \mathrm{H} 36 \mathrm{O} 2$ & 284 & 7.53 \\
\hline 8.53 & 11,14-Eicosa dienoica cid & $\mathrm{C} 2 \mathrm{OH} 36 \mathrm{O} 2$ & 308 & 0.06 \\
\hline 8.99 & (E)7- Nonadecenoic & $\mathrm{C} 19 \mathrm{H} 36 \mathrm{O} 2$ & 296 & 0.84 \\
\hline 9.36 & arachidic acid & $\mathrm{C} 2 \mathrm{OH} 40 \mathrm{O} 2$ & 312 & 0.16 \\
\hline
\end{tabular}

98.4 min was optimized using Response surface methodology. the unsaturated fatty acids occupy $63.92 \%$ of the total fatty acids. The analytical results of GC-MS showed that abundant unsaturated fatty acids such as oleic acid and linoleic acid accounted for $63.92 \%$ of total fatty acids.

\section{CONFLICT OF INTEREST}

The authors confirm that this article content has no conflict of interest.

\section{ACKNOWLEDGEMENTS}

The authors acknowledge the financial support provided by grants from the National Natural Science Foundation of China (No.11102092); Science and Technology Key Project of Education Department in Henan Province (No. 12B130003); and Biochemistry and Molecular Biology Key Discipline of Henan Province. 


\section{REFERENCES}

[1] Bailey-Shaw YA, Golden KD, Pearson AG, Porter RB. Characterization of Jamaican agro-industrial wastes. Part II, fatty acid profiling using HPLC: precolumn derivatization with phenacyl bromide. J Chromatogr Sci 2012; 50(8): 666-72.

[2] D'Oca MG, Moron-Villarreyes JA, Lemoes JS, Costa CS. Fatty acids composition in seeds of the South American glasswort Sarcocornia ambigua. An Acad Bras Cienc 2012; 84(3): 865-70.

[3] de Paiva SR, Lima LA, Figueiredo MR, Kaplan MA. Plumbagin quantification in roots of Plumbago scandens L. obtained by different extraction techniques. An Acad Bras Cienc 2004; 76(3): 499-504.

[4] Li P, Lu S, Shan T, et al. Extraction optimization of waterextracted mycelial polysaccharide from endophytic fungus fusarium oxysporum dzf17 by response surface methodology. Int J Mol Sci 2012; 13(5): 5441-53.

[5] Li X, Wang Z, Wang L, Walid E, Zhang H. Ultrasonic-assisted extraction of polysaccharides from Hohenbuehelia serotina by response surface methodology. Int J Biol Macromol 2012; 51(4): 523-30.

[6] Liu N, Liu JT, Ji YY, Lu PP. Dahuang zhechong pill containing serum inhibited platelet-derived growth factor-stimulated vascular smooth muscle cells proliferation by inducing G1 arrest partly via suppressing protein kinase $\mathrm{C}$ alpha-extracellular regulated kinase 1/2 signaling pathway. Chin J Integr Med 2012; 18(5): 371-7.

[7] Ma D, Li Y, Dong J, et al. Purification and characterization of two new allergens from the salivary glands of the horsefly, Tabanus yao. Allergy. 2011; 66(1): 101-9.
[8] Ma D, Wang $\mathrm{Y}$, Yang $\mathrm{H}$, et al. Anti-thrombosis repertoire of blood-feeding horsefly salivary glands. Mol Cell Proteomics 2009; 8(9): 2071-9.

[9] Ma D, Xu X, An S, et al. A novel family of RGD-containing disintegrins (Tablysin-15) from the salivary gland of the horsefly Tabanus yao targets alphaIIbbeta3 or alphaVbeta3 and inhibits platelet aggregation and angiogenesis. Thromb Haemost 2011; 105(6): 1032-45.

[10] Maldonado RA, Kuniyoshi RK, Linss JG, Almeida IC. Trypanosoma cruzi oleate desaturase: molecular characterization and comparative analysis in other trypanosomatids. J Parasitol 2006; 92(5): 1064-74.

[11] McNichol J, MacDougall KM, Melanson JE, McGinn PJ. Suitability of Soxhlet extraction to quantify microalgal Fatty acids as determined by comparison with in situ transesterification. Lipids 2012; 47(2): 195-207.

[12] Naqvi AZ, Davis RB, Mukamal KJ. Dietary fatty acids and peripheral artery disease in adults. Atherosclerosis 2012; 222(2): 545-50.

[13] Paiva SR, Lima LA, Figueiredo MR, Kaplan MA. Chemical composition fluctuations in roots of Plumbago scandens $\mathrm{L}$. in relation to floral development. An Acad Bras Cienc 2011; 83(4): 1165-70.

[14] Rao G. Optimization of ultrasound-assisted extraction of cyanidin 3-rutinoside from litchi (Lichi chinensis Sonn.) fruit pericarp. Anal Methods 2010; 2(8): 1166-70.

(C) Yanhua et al.; Licensee Bentham Open.

This is an open access article licensed under the terms of the Creative Commons Attribution Non-Commercial License (http://creativecommons.org/licenses/by-nc/3.0/) which permits unrestricted, non-commercial use, distribution and reproduction in any medium, provided the work is properly cited. 